This is the version of the article accepted for publication in Human Relations published by SAGE https://doi.org/10.1177/0018726717729208

Accepted version downloaded from SOAS Research Online: http://eprints.soas.ac.uk/31928/

THE POLITICS OF CULTURAL CAPITAL: SOCIAL HIERARCHYAND

ORGANIZATIONAL ARCHITECTURE IN THE MULTINATIONAL

CORPORATION

\author{
Orly Levy, Ph. D. \\ School of Management \\ Cranfield University \\ Cranfield, Bedfordshire MK43 0AL \\ +44 1234751122 \\ o.levy@cranfield.ac.uk \\ B. Sebastian Reiche, Ph. D. \\ Department of Managing People in Organizations \\ IESE Business School \\ Ave. Pearson 21 \\ 08034 Barcelona, Spain \\ +34936024491 \\ sreiche@iese.edu
}

Forthcoming in Human Relations special issue 'Politicization and political contests in contemporary multinational corporations' 


\title{
The politics of cultural capital: Social hierarchy and organizational architecture in the multinational corporation
}

Orly Levy and B Sebastian Reiche

\begin{abstract}
How is social hierarchy in multinational corporations (MNCs) culturally produced, contested and reproduced? While the international business literature has acknowledged the importance of culture, it gives little concern to its role in constructing social hierarchies and symbolic boundaries between individuals and groups within MNCs. We take a Bourdieusian approach to understanding the role of cultural capital in structuring the social hierarchy in the MNC under two contrasting organizational architectures: hierarchical and network architecture. We argue that cultural capital serves as an instrument of power and status within the MNC, influencing access to valuable resources such as jobs, rewards, and opportunities. Our framework further suggests that the transition from hierarchical towards network architecture sets in motion a high-stakes political struggle between headquarters and subsidiary actors over the relative value of their cultural capital in a bid to preserve or gain dominance and to determine the 'rules of the game' that order the social hierarchy in the MNC. We elaborate on this political struggle by theorizing about the relative dominance of cultural versus social capital, the content and relative value of firm-specific and cosmopolitan cultural resources, and the convertibility of cultural capital into other forms of capital under hierarchical and network architectures.
\end{abstract}

\section{Keywords}

Bourdieu; cultural capital; MNC, multinational corporation; organizational architecture; social capital; social hierarchy 


\section{Introduction}

Culture and cultural processes figure prominently in international business (IB). However, research has been dominated by essentialist analyses that have objectified cultural characteristics and reified cultural differences (Vaara, Tienari and Säntti, 2003), focusing on the core dimensions of national cultures (i.e., cultural norms, values, and practices) and cultural distance between countries. Much less attention has been given to the role of culture in the construction and reproduction of power relations and symbolic boundaries between individuals and groups within the multinational corporation (MNC). Thus, while research has identified a host of cultural consequences, it has largely overlooked the questions of how cultural resources underlie the social hierarchy within the MNC and how these are used 'both as weapons and as stakes' in the struggle to gain ascendancy over the organization (Emirbayer and Johnson, 2008: 11, emphasis in original).

Social hierarchies are prevalent across a broad range of social organizations (Gould, 2002), including complex and diverse organizations such as MNCs. They can be viewed as a mechanism — formal or informal — that ranks individuals and groups on the basis of socially valued dimensions (Magee and Galinsky, 2008) or various forms of capital (i.e., economic, social, cultural) (Bourdieu, 1986). Thus, individuals and groups are sorted into 'social positions that carry unequal rewards, obligations, and expectations' (Gould, 2002: 1143) based on their capital endowment. One of the most important forms of capital is cultural capital, defined as a corpus of cultural resources, including knowledge, dispositions, and objects that is valued within a particular field of social action (Bourdieu, 1986). Cultural capital is often used by dominant groups to construct status and power distinctions between individuals and groups and to legitimize their relative positions in the social hierarchy (Bourdieu, 1984). Cultural capital and the social hierarchy are therefore mutually 
constitutive, sorting individuals and groups into more or less advantageous positions in the social structure according to their capital endowments. However, IB research has focused almost exclusively on strategic and economic rationales, giving very little consideration to the underlying cultural logic and social meaning of these social positions and roles (Levy et al., 2015).

As MNCs go through major organizational transformations, the principles that order the social hierarchy and define what constitutes cultural capital or valuable cultural resources are in play. In fact, what may be at stake during these transformations is nothing less than the capacity to determine which contrasting forms of cultural capital will be most influential for gaining status and power in the MNC and for determining its activities and policies (Emirbayer and Johnson, 2008; Fligstein, 1990). In particular, as MNCs move away from hierarchical towards network organizational architecture (Hedlund, 1993; Menz, Kunisch and Collis, 2015), what may be at stake is which cultural resources - those held by headquarters (HQ) actors or those held by subsidiary actors — or, more broadly, whether cultural or social capital will emerge as relatively more dominant. However, mainstream research has failed to recognize these stakes and mostly ignored the role of culture and power in major organizational transformations, describing them largely in evolutionary terms rather than as sites of political conflicts (Geppert and Dörrenbächer, 2014). Consequently, the political struggle among holders of different forms of capital in the bid to preserve or gain dominance has remained largely unexplored (Levy et al., 2015).

In this article, we seek to address these gaps in the literature by offering a theoretical framework that conceptualizes the role of cultural resources and political processes in structuring the social hierarchy in two contrasting organizational architectures of the MNC: hierarchical and network architecture. Drawing on the work of Bourdieu and colleagues 
(Bourdieu, 1984, 1986; Bourdieu and Passeron, 1979, 1990), we suggest that cultural capital is used as an instrument of power and status within the MNC, enabling the dominant groups to monopolize privileges and exclude those deemed culturally inapt or culturally distant from high-status positions (Bourdieu, 1984). Thus, we argue that cultural capital underlies the social hierarchy in the MNC and influences access to valuable resources such as rewards and opportunities. Our analysis focuses primarily on cultural capital because we argue that it serves as an exceptionally dominant form of capital in the MNC under both hierarchical and network architectures. We do not directly consider economic capital because in those social fields where the dominant currency is cultural capital, financial and other tangible assets are largely a by-product of cultural capital (Bourdieu, 1985).

In our analysis, we focus on a particular processual element of political activity, that of politicization, which refers to challenges to established power structures (Palonen, 2003). Specifically, we suggest that the transformation from hierarchical architecture towards network architecture sets in motion a high-stakes political struggle between HQ and subsidiary actors over the principles that govern the recognition and legitimization of cultural resources, and order the social hierarchy in the MNC. Thus, the dominant form of cultural capital under hierarchical architecture may experience devaluation and lose its currency whereas other forms of cultural capital can emerge as influential under the network architecture of the MNC. We identify two forms of cultural capital—firm-specific and cosmopolitan - that may be subject to redefinition and revaluation as a result of the organizational transformation. Additionally, such transformation can potentially affect the salience of cultural capital relative to other forms of capital, particularly social capital, for ordering the social hierarchy within the MNC. Finally, we suggest that such transformation is likely to create a global political game where a larger number of actors, holding different 
forms of capital, jockey for social positions in the field of power (Kristensen and Zeitlin, 2005).

Through contrasting two prevalent and ideal-typical organizational architectures of the MNC, we make the following theoretical contributions. First, while the production and reproduction of social hierarchy has been widely studied from both psychological (e.g., Coté, 2011) and sociological (e.g., Simpson, Willer and Ridgeway, 2012) approaches, it has received scant attention from organizational scholars in general and from the IB literature in particular. More specifically, existing work in IB tends to focus on the organizational level with little concern for how social hierarchy and power differences are generated at the interor intra-unit level within MNCs (Geppert, Becker-Ritterspach and Mudambi, 2016). We demonstrate how actors' locale-specific embeddedness within the MNC determines the cultural resources they can leverage to attain a favourable position in the MNC's social hierarchy, and how changes in structural configuration enable peripheral actors to 'upgrade' their capital endowments and compete for social status. In doing so, we explicitly link structural features, which continue to serve as a salient source of power differences in MNCs, with how actors actively shape existing power relations (Geppert and Dörrenbächer, 2014; Geppert et al., 2016). We also challenge the conventional wisdom and propose that although the network MNC is often presented as 'differentiated' (Bartlett and Ghoshal, 1989; Hedlund, 1993; Menz et al., 2015) rather than stratified, it nevertheless gives rise to a social hierarchy based on different forms of capital. We theorize about the unintended consequences of the network MNC, suggesting that its supposedly dehierarchical and lateral nature leads, in fact, to the emergence of social hierarchy as a mechanism of control and coordination.

Second, we adopt a political perspective to analyze the cultural processes that produce social hierarchy in MNCs. Although a growing literature examines the ways in which 
organizational life is culturally constructed (e.g., Weber and Dacin, 2011), the IB field is largely limited to objective-like manifestations of culture and essentialized cultural differences. Our theorizing suggests that culture is both a political resource and a constraint that stratifies power and status between employee groups in $\mathrm{MNCs}$, and by extension affects the relative salience of social capital. Third, our framework has implications for the study of cultural capital. Specifically, we highlight the changing nature of the concept of cultural capital that is not limited to organizational and professional facets but also includes a cosmopolitan dimension (see also Prieur and Savage, 2013) as it increasingly operates in a transnational social space, is modified through structural changes, and potentially accumulated by a broader group of organizational actors than traditionally assumed.

In the following sections, we take a Bourdieusian approach to study the interrelations between cultural capital and social hierarchy in MNCs. We first discuss how cultural capital serves to produce and reproduce social hierarchy in the organization-as-a-field, and apply these ideas to structural configurations and particular actor groups in the MNC context. We then theorize about the role of cultural resources and political processes in structuring the social hierarchy as MNCs transition from hierarchical to network architecture. We conclude with a discussion and implications for theory, practice, and future research.

\section{The-organization-as-a-field and cultural capital}

Bourdieu defines the-organization-as-a-field as a network, or a configuration, of objective relations between positions anchored in certain forms of power or capital (Bourdieu and Wacquant, 1992). Thus, the concept of field denotes a force field where the distribution of capital establishes and reproduces a hierarchical set of power relations among positions and among the actors who occupy them (Swartz, 1997). The field can therefore be viewed as 
'networks of social relations, structured systems of social positions within which struggles or manoeuvres take place over resources, stakes, and access' (Oakes, Townley and Cooper, 1998: 260). For Bourdieu (1986), each actor occupies a social position in the space of power due to the composition and volume of his or her capital endowment. In turn, this capital endowment enables the actor to operate effectively within the field and compete for resources and social positions (Emirbayer and Johnson, 2008).

Bourdieu (1986) distinguishes between three primary forms of capital that actors can possess - each assuming field-specific content and value (Bourdieu and Wacquant, 1992). Economic capital refers to financial resources or assets that have a monetary value. Social capital is the sum of the actual and potential resources that can be mobilized through membership in social networks (Bourdieu, 1986). Cultural capital exists in various forms, including knowledge and expertise, formal credentials, as well as longstanding habitus, a system of behavioral and attitudinal dispositions acquired through the socialization process (Emirbayer and Johnson, 2008; Lamont and Lareau, 1988). Finally, Bourdieu (1986) introduces symbolic capital, commonly understood as prestige and honour accrued as a result of social recognition of the value of cultural, social, and/or economic capital. Thus, the notion of symbolic capital captures the 'symbolic effects of capital' when it is perceived and recognized as legitimate (Bourdieu, 2000: 242, emphasis in original; see also Kerr and Robinson, 2016).

Our focus is on cultural capital and the role of cultural resources in structuring social hierarchies, power relations, and symbolic boundaries between individuals and groups (Lamont and Lareau, 1988; Robbins, 2005). According to Bourdieu (1984; Bourdieu and Passeron, 1979, 1990), the cultural resources of the dominant classes (i.e., upper class, uppermiddle and middle class), including cultural knowledge, tastes, preferences, attitudes and 
behaviors, become cultural capital, thereby serving as a class signal. As such, cultural capital helps to reproduce domination by marking cultural distance and proximity, monopolizing privileges, and excluding and recruiting new occupants for high-status positions (Lamont and Lareau, 1988). Furthermore, cultural capital can be used to gain access to scarce rewards and opportunities and is subject to monopolization and hoarding (Lareau and Weininger, 2003). Consequently, culture is viewed as key in the construction and reproduction of domination and hierarchy through the legitimization and appropriation of cultural knowledge (Lareau, 2015).

Research has focused on several cultural resources as valuable cultural capital in the workplace (e.g., Davies-Netzley, 1998; Friedman, Laurison and Miles, 2015; Kaplan, 2006; Kay and Hagan, 1998; Purcell, 2013; Rivera, 2012; Stuber, 2005). For example, Kay and Hagan (1998) found that cultural capital, manifested as a firm-specific disposition that is aligned with the culture or goals of the firm, significantly influenced the likelihood of women becoming partners in law firms. Purcell (2013) identified three forms of cultural capital— knowledge about informal expectations in the workplace, ability to navigate a range of informal social events, and knowledge about popular culture — as valuable cultural resources in a large retail company. Rivera (2012) identified cultural similarities in taste, leisure pursuits, and self-presentation styles between potential employers and job candidates as cultural capital and suggested that these influenced hiring decisions. These studies suggest that cultural knowledge and resources are used to sort employees into organizational and social positions in the workplace and affect their rewards and opportunities.

\section{The multinational corporation architecture and cultural capital}


According to Bourdieu, there is a close correspondence between the structural configuration of the field and the form(s) of capital that are dominant within the field (Bourdieu, 1985). Conversely, the predominance of economic, social, or cultural capital is a characteristic of different fields of social action and results in different structural configurations (Anheier, Gerhards and Romo, 1995). For example, a predominance of cultural capital tends to lead to highly segmented and hierarchical social structures whereas a predominance of social capital leads to multiple though weakly institutionalized segments (Anheier et al., 1995). Therefore, ascertaining the nexus of field and capital involves a hermeneutic circle: 'in order to construct the field, one must identify the forms of specific capital that operate within it, and to construct the forms of specific capital one must know the specific logic of the field' (Bourdieu and Wacquant, 1992: 108). Determining the structural configuration of the MNC-as-a-field at a given point of time involves identifying three key elements: (a) the logic of the organizational architecture of the MNC; (b) the dominant actors or groups who are able to accumulate and deploy valuable capital within the MNC; and (c) the dominant form(s) of capital within the MNC underlying the power relations among actors (Emirbayer and Johnson, 2008). Below, we discuss each of these elements.

We primarily consider cultural capital because we view it as the operative, yet largely ignored, form of capital in the MNC, exerting significant influence on the social hierarchy in both hierarchical and network architectures. As such, it 'determines the aggregate chances of profit in all games..., thereby helping to determine positions in the social space' (Bourdieu, 1985: 724). Further, economic capital involves weaker segmentation of the social structure and more fluid hierarchy relative to the other forms of capital and can be conceived as an outcome of the other forms of capital (Anheier et al., 1995). 
The IB literature has commonly conceptualized two alternative logics of MNC architecture that continue to characterize contemporary MNCs (Bouquet, Barsoux and Levy, 2015; Geppert et al., 2016), contrasting traditional hierarchical with more decentralized and less formalized network architectures (Birkinshaw and Morrison, 1995; Menz et al., 2015). The traditional hierarchical—or hub-and-spoke—-model constitutes an organizational structure in which each foreign subsidiary is linked to and controlled by HQ, and most resources flow either directly or indirectly through HQ (Bartlett and Ghoshal, 1989). In contrast, network architecture, which subsumes varied conceptualizations such as heterarchy (Hedlund, 1993), multi-focal firm (Prahalad and Doz, 1987), transnational (Bartlett and Ghoshal, 1989), metanational (Doz, Santos and Williamson, 2001), and federation (Andersson, Forsgren, and Holm, 2007), is characterized by increasingly interdependent and informal mechanisms of coordination, control and resource mobilization. Research has discussed several dimensions along which these two ideal-typical architectures differ, including the distribution of authority, range of resource mobilization, and coordination and control mechanisms (Bartlett and Ghoshal, 1989; Birkinshaw and Morrison, 1995; Hedlund, 1993; Martinez and Jarillo, 1989). Table 1 outlines these differences.

\section{Insert Table 1 about here}

Research on the transition from hierarchical architecture towards network architecture of the MNC often describes this process in evolutionary terms, prompting MNCs to align their structure and internationalization strategies with demands of the external environment (Geppert and Dörrenbächer, 2014; Westney, 2009). Thus, from an evolutionary perspective the transition from hierarchal to network architecture is often presented as an adaptive 
response to environmental pressures where the adoption of a 'superior' organizational architecture is thought to secure survival. However, initial evidence suggests that this shift is a contested political process (e.g., Whitford and Zirpoli, 2016) rather than a 'natural' stage in an evolutionary process or an inevitability propelled by the superiority of informal mechanisms of collaboration and control such as lateral decision-making and normative integration (Bartlett and Ghoshal, 1989; Hedlund, 1993). Nevertheless, the role of power in such transitions and the effect of such transitions on the configuration of power relations and status hierarchies in the MNC are rarely explicitly considered. Specifically, mainstream evolutionary approaches to the study of MNCs commonly consider bottom-up political action as dysfunctional and to be curbed by the HQ through normative integration (Geppert and Dörrenbächer, 2014). At the same time, the reliance on normative integration as a control mechanism in network MNCs allows for subsidiary autonomy, with authority emerging laterally, and hence encourages subsidiary actors to become politically active (Williams and Lee, 2011).

Despite the relevance of culture for the production of social hierarchy following a shift in the logic(s) of the organizational architecture very little research has examined the role of cultural capital. In the following, we will theorize about how changes in the structural configuration of the MNC affect the definition of valuable cultural resources and the dominance of cultural versus social capital.

\section{Dominant actor groups}

Examining political conflict within the MNC context requires identifying the relevant actor groups that compete for social status (Becker-Ritterspach and Dörrenbächer, 2009) and struggle for recognition of their cultural resources (Levy et al., 2015). Here, we draw on 
previous conceptualizations to distinguish between actors associated with HQ and with subsidiaries (Clark and Geppert, 2011; Delmestri and Brumana, 2017; Ferner, Edwards and Tempel, 2012). The relative dominance of HQ vis-à-vis subsidiary actors is considered the most important organizing principle of MNC activities, as evidenced by the large body of literature on the topic (for recent analyses, see Andersson and Holm, 2010; Boussebaa and Morgan, 2014). We recognize that $\mathrm{HQ}$ and subsidiary actors may differ with regard to their relative individual sources of power. For example, individual actors may be endowed with differential hierarchical status, resource control and network centrality both within and beyond their own unit (Reiche, Harzing, and Kraimer, 2009) or dispose of different discursive resources (Whitford and Zirpoli, 2016). Similarly, individual MNC units may differ in their relative power according to their level of internal embeddedness - the linkages with other MNC units—as well as their level of external embeddedness with outside stakeholders in their local environment (Bouquet and Birkinshaw, 2008). Still, the HQsubsidiary relationship continues to serve as the primary axis of power relations within MNCs (e.g., Geppert and Dörrenbächer, 2014) and is therefore key in the recognition and legitimacy of cultural resources in the MNC.

It is important to note, however, that although the HQ is often conceived as strategically omniscient, agency is not limited to HQ actors (Geppert and Dörrenbächer, 2014; Kristensen and Zeitlin, 2005). For example, previous research has highlighted that subsidiary managers can enhance their power base relative to $\mathrm{HQ}$ actors through the control of R\&D resources (Mudambi and Navarra, 2004), control of the subsidiary's local business network (Andersson et al., 2007), issue-selling (Dörrenbächer and Gammelgaard, 2016), initiative taking and profile building (Bouquet and Birkinshaw, 2008), and interpersonal and cross-boundary networking (Williams and Lee, 2011). 
Given the HQ's greater power over resources, processes and meaning compared to subsidiaries, both in terms of the number of issues for which HQ actors can determine outcomes and the number of contexts for which these dominance effects apply (Lukes, 2005; Ferner et al., 2012), a shift from hierarchical to network architecture may not result in a fundamental redistribution of capital endowments from HQ to subsidiary actors. Nevertheless, such transformation could have a significant effect because it destabilizes the field of power of the MNC and sets off a fierce competition for social positions where subsidiary actors are no longer mere spectators but rather serious contenders. Furthermore, the boundaries of the HQ organization as the main site for political struggle may become more fluid and permeable. Hence, we expect the structure of power relations within the MNC and the relative dominance of HQ actors to shift as a result of the transformation of the organizational architecture and the ensuing changes in relative value and salience of different forms of capital.

\section{Form(s) of cultural capital in the multinational corporation}

Cultural capital in the MNC reflects the values, normative standards, and expectations of the dominant groups in the organization; these are used to define both the embodied and institutionalized states of cultural capital within the firm. Embodied cultural capital reflects the legitimate cultural attitudes, preferences, and behaviors (or practices) that are acquired and internalized through socialization processes. Institutionalized cultural capital refers to formal or certified credentials such as educational degrees and diplomas, as well as expertise and skills; these are used to underpin the value of embodied cultural capital. ${ }^{1}$ Cultural capital, especially in its embodied state, often goes unrecognized as capital because its transmission and acquisition are more disguised than those of economic capital; it therefore functions as 
symbolic capital, i.e., recognized as a legitimate competence (Bourdieu, 1986). Our focus is on two primary forms of cultural capital that may operate within the MNC: firm-specific cultural capital and cosmopolitan cultural capital.

Firm-specific cultural capital is internal and specific to a particular MNC; it represents those cultural resources that are operative within the organization-as-a-field and enable actors to function effectively within the MNC. These resources are developed and accumulated within a specific firm and are particularly valued in this context. Thus, firmspecific cultural capital represents cultural proficiency in the tacit normative and cognitive 'rules of the game' (Clegg, 1989) that govern the way things are done in the MNC; these rules also define the right or desirable dispositions, attitudes, and behaviors for employees working in the MNC. Employees who are proficient in the firm's cultural norms, meanings, and rituals and can play the part are judged to be bona fide members of the organization. They are therefore more likely to gain access to rewards and opportunities within the MNC. Accordingly, this aspect of firm-specific cultural capital creates distinctions between employees on the basis of their cultural dispositions and proficiencies as organizational members, resulting in inclusion and exclusion of employees from rewards and opportunities (Lamont and Lareau, 1988; Lareau and Weininger, 2003).

Firm-specific cultural capital can also involve proficiency in a professional corpus of knowledge and expertise that is valued within the MNC. While many MNCs ostensibly subscribe to the ideal that there are universal standards for judging professional performance and knowledge, in reality these evaluation criteria are often set by the dominant groups in the firm. They reflect a distinct interpretation of what it means to be a professional in a particular firm rather than a more general professional orientation (e.g., Kay and Hagan, 1998), or universal professional standards. Further, they also involve the often unspoken rules 
concerning how knowledge and expertise are judged and evaluated within the firm. Thus, cultural capital also creates distinctions between employees on the basis of their professional expertise, knowledge and credentials as judged by the powers that be; employees who demonstrate cultural proficiency and are thought to be the right kind of professional (Kay and Hagan, 1998) receive greater rewards.

Finally, firm-specific cultural capital is often influenced by the home country of the MNC. Thus, elements of 'national' cultural capital — cultural resources that are valued in the home country of the MNC and are often accumulated through the home country educational system - are frequently incorporated into firm-specific cultural capital. For example, a recent survey of French multinationals indicated that these organizations continue to be dominated by a network of graduates of the elite grandes écoles and that proficiency in French was essential to reaching the boardroom (The Economist, 2015). Thus, while the MNC is considered a semi-autonomous field that produces and legitimizes its own cultural resources, some of these cultural resources are often derived from the national level and mirror the values and norms of the home country.

While firm-specific cultural capital reflects a particular amalgamation of values, standards, and expectations, cosmopolitan cultural capital is not defined within the confines of a particular firm and is thus considered both external and more universal. Cosmopolitan cultural capital (also called global cultural capital) can be viewed as bodily and mental predispositions and competencies that facilitate skilful and confident engagement in transnational activities (Weenink, 2008: 1092). It also involves a discernible set of practices and experiences such as international work experience, international education (often in elite schools), and international mobility (Bühlmann and Mach, 2013; Igarashi and Saito, 2014; Kim, 2011; Levy, Peiperl and Jonsen, 2016). A person who possesses cosmopolitan cultural 
capital or claims to be a cosmopolitan can thus display knowledge, taste, and lifestyle that 'stand outside one's own national frame of reference' (Prieur and Savage, 2013: 259); he or she is often familiar with products and people from diverse cultures and feel at ease when operating across national borders. In many MNCs, this form of knowledge and expertise has acquired the characteristics of cultural capital because of its almost universal legitimacy, desirability, and unequal access (Igarashi and Saito, 2014). As such, it is often used to construct symbolic boundaries between employee groups through defining cosmopolitan knowledge and experience as valuable and delegitimizing other cultural resources by labelling them local, parochial, or outdated (Bourgouin, 2012; Lamont and Molnár, 2002).

\section{Cultural capital and the production of social hierarchy under changing MNC architectures}

In this section, we theorize about the role of cultural resources and political processes in structuring the social hierarchy in the MNC. To focus our theoretical analysis, we contrast two prevalent and ideal-typical organizational architectures of the MNC: hierarchical and network architecture (e.g., Birkinshaw and Morrison, 1995; Bouquet et al., 2015; Geppert et al., 2016; Menz et al., 2015). Furthermore, we analyse the transition from hierarchical to network architecture as an iconic organizational transformation that demonstrates the political processes through which the social hierarchy in the MNC is produced, contested, and reproduced. Specifically, we contend that the transition from hierarchical to network architecture is highly political and contested because it affects the relative status of HQ and subsidiary actors and alters the value of their capital endowments. Our argument is threefold. First, cultural capital is the dominant form of capital in hierarchical architecture, which is typical of highly segmented and hierarchical social structures (Anheier et al., 1995; Bourdieu, 
1984). In network architecture social capital across the MNC is considered the most valuable currency. Thus, the transition from hierarchical to network architecture can potentially destabilize the social hierarchy and the relative value of cultural versus social capital, although we would argue that cultural capital retains a decisive influence on the social hierarchy even in a network MNC.

Second, the structural transformation from hierarchical to network architecture is likely to affect the definition of valuable cultural resources or which of the various forms of cultural capital extant within the MNC will be the most influential in defining the activities and boundaries of the firm (Emirbayer and Johnson, 2008). Therefore, the competition for domination over the changing field often manifests itself as a struggle over which form(s) of cultural capital will generate power, authority, and symbolic profit. Specifically, the relative value of the dominant cultural resources can diminish or undergo devaluation while the value of cultural resources previously undervalued can increase or become legitimized. Further, the new context can create a heightened demand to a particular set of cultural resources and, as a result, these resources can undergo overvaluation, generating higher-than-normal returns and symbolic profits. Hence, those who hold dominant forms of capital are likely to enact conservation strategies in order to preserve the supremacy of their brand of capital and to defend or even enhance their position within the social hierarchy. In contrast, those who hold undervalued or non-dominant forms of capital are likely to enact subversion strategies in order to transform the prevailing system of power relations and authority within the field to their own benefit (Emirbayer and Johnson, 2008). Thus, the worth of cultural resources is at stake during the transformation, prompting actors to engage in a struggle over their valuation and legitimization. 
Third, cultural capital plays a dual role in the transformation from hierarchical to network architecture. On the one hand, cultural capital operates as stakes in the field because the transformation is likely to affect which cultural resources - those held by HQ actors or those held by subsidiary actors - or, more broadly, whether cultural or social capital will emerge as relatively more dominant in the MNC-as-a-field. On the other hand, cultural capital may be used as a weapon in the struggle for legitimacy and authority to shape the transformation and define which cultural resources will be considered valuable. In this respect, cultural capital operates as symbolic capital, thereby concealing the arbitrariness of a particular set of cultural resources as a source of power and domination and presenting them as a legitimate competence (Bourdieu, 1986, 1994).

Taken together, our arguments suggest that the transition from hierarchical to network architecture affects the capital endowment of HQ and subsidiary actors, and thereby their relative position in the social hierarchy. Even when the transformation is not deliberately oriented toward the current state of power relations in the MNC, it has an effect on the configuration of these relations, an effect that may either be perpetuative or transformative in nature (Emirbayer and Johnson, 2008). Thus, key MNC actors stand to lose and gain during this transition and will engage in a political struggle over the recognition and legitimization of their capital endowments.

Below, we further elaborate these arguments and discuss the influence of this transition on the dominant forms of capital in the $\mathrm{MNC}$, the locus and content of firm-specific cultural capital, the relative value of firm-specific and cosmopolitan cultural capital, and the exchange rate of cultural capital into other forms of capital. Table 2 summarizes these arguments. 


\section{Insert Table 2 about here}

Dominant forms of capital and the multinational corporation architecture

According to Bourdieu (1985) the dominance of specific forms of capital is characteristic of different types of social fields. Thus, the social hierarchy in different social fields is anchored in one form of capital or another, or in a particular combination of forms of capital (Anheier et al., 1995). In hierarchical architecture cultural capital is the dominant form of capital, which is typical of highly segmented and highly hierarchical social fields (Anheier et al., 1995; Bourdieu, 1984). Specifically, cultural resources tend to be classified and rankordered according to their supposedly 'inherent' quality and value. ${ }^{2}$ Such classifications lend themselves to the construction of social hierarchies and the division of the social structure into a segment that produces legitimized or valuable cultural resources, and another segment of non-legitimate or low-value cultural resources. The relationship between these two segments is hierarchical (Anheier et al., 1995). Therefore, cultural resources serve as the foundation of social hierarchies, providing a veneer of (cultural) logic and conferring legitimacy on status distinctions that may otherwise seem arbitrary.

Thus, under hierarchical architecture, the MNC-as-a-field is divided into a dominant segment - the HQ organization — that produces and controls the legitimized cultural resources, and dominated segments_-foreign subsidiaries - that do not possess or have access to legitimate cultural resources. Further, HQ actors, for whom cultural capital is a very important currency, are stratified according to their cultural capital endowment and engage in competition for social positions, rewards, and opportunities. In contrast, cultural capital is less important for subsidiary actors in gaining access to rewards and opportunities outside their subsidiary unit because their social status is likely to be primarily determined by their 
peripheral structural position in the MNC. In this regard, cultural capital acts as a coordination and control mechanism within the HQ organization (Magee and Galinsky, 2008) and as an exclusion and marginalization mechanism vis-à-vis subsidiaries. It is a coordination mechanism because cultural capital creates social hierarchy and social hierarchy facilitates order and collaborative action. It also serves a control function because individuals are motivated to achieve rewards and progress to higher organizational ranks that are ordered according to organizational performance. While subsidiary actors' specific career ambitions may affect the motivational impact of cultural capital (Clark and Geppert, 2011; Morgan and Kristensen, 2006), in the case of asymmetrical power relations the HQ retains the ultimate influence over reward (see Dörrenbächer and Gammelgaard, 2016).

In comparison, social capital is less valuable in hierarchical architecture because resources are mobilized mainly vertically through a potent formal hierarchy that places the HQ above other MNC units (e.g., Birkinshaw and Morrison, 1995). In addition, inter-unit coordination and control occur primarily through formal and structural mechanisms (Martinez and Jarillo, 1989), which leads to a tighter coupling across MNC units (Orton and Weick, 1990) and results in the social hierarchy being closely aligned with the formal organizational hierarchy. Note that social capital continues to serve as an important currency within a particular MNC unit. For example, social relationships with influential subsidiary actors should help low-power actors in that subsidiary access valuable resources and pursue their career interests (Seibert, Kraimer, and Liden, 2001). However, in a highly segmented social field such as the hierarchical MNC it is more difficult to develop and maintain informal linkages - and transfer the associated social resources (Lin, Ensel, and Vaughn, 1981)—from one segment to another. 
In network architecture social capital serves as the dominant form of capital, which is typical of complex social networks characterized by multiple segments that are differentiated rather than hierarchical (Anheier et al., 1995). Research suggests that resources in a network architecture are distributed across the MNC and are potentially accessible through both formal and informal means, hence the importance of developing and maintaining inter-unit social capital (Reiche et al., 2009; Williams and Lee, 2011). The literature also discusses the role of normative integration in the form of shared values and beliefs as a substitute means of subsidiary control at the hands of HQ (Nohria and Ghoshal, 1994). However, the emphasis in IB research on normative and social integration has overshadowed the role of power and politics in the network MNC (Geppert and Dörrenbächer, 2014).

Specifically, we argue that the informal, lateral and decentralized structure of a network organization leads to the emergence of cultural capital as an important coordination and control mechanism under conditions of uncertainty, complexity, and heightened political activity. Further, as the informal structure of a network architecture creates a fertile ground for power and status enhancing activities (see Whitford and Zirpoli, 2016), there is a strong need to curb and coordinate these activities. In this context, cultural capital and the social hierarchy it produces serve as important means of coordination and control. Specifically, in situations of high uncertainty, as in the case of spatially dispersed and loosely coupled interactions in network architecture, actors rely on observable characteristics to gauge quality and outputs, and status rankings and reputation act as a relevant and visible signalling mechanism (Sauder, Lynn and Podolny, 2012). In the absence of formal mechanisms of control and coordination, cultural capital and the associated social status help coordinate collective action by regulating how and when individuals should contribute to group efforts (Simpson et al., 2012). Further, status hierarchy exerts control by motivating individuals to 
progress to higher organizational ranks (Magee and Galinsky, 2008), according to the rules of the game that are embedded within it. Thus, we suggest that the decentralized and lateral characteristics of a network structure has unintended consequences, giving rise to a social hierarchy based on cultural and social capital, which are likely to be mutually reinforcing. Further, as both HQ and subsidiary actors share a common political arena in the network architecture and engage in competition for social positions, social and cultural capital are likely to be important not only within the HQ organization but also across the MNC.

\section{Locus and content of firm-specific cultural capital}

In hierarchical architecture, the field of power is bifurcated and authority is concentrated at the HQ and in the home country. As a result, HQ actors, the majority of whom are parent country nationals, form the dominant group in the MNC. As such, they have the power to legitimize their own cultural resources and delegitimize those of others through the management of meaning and symbolic action (Hardy, 1996). Hence, HQ actors monopolize the production and accumulation of symbolic capital whereas subsidiary actors bear what can be conceived as 'negative symbolic capital' (Bourdieu, 2000: 241). According to Ferner et al. (2012), HQ actors have greater power than subsidiaries over meaning and can therefore shape the cognitive and normative rules of the game by influencing the corporate culture, identity, and value system (Kostova, 1999). Further, HQ actors have many more socialization opportunities that enable them to master the rules of the game, which are often tacit and implicit, and to develop proficiency in playing the organizational game. Therefore, HQ actors can accumulate significant firm-specific cultural capital by demonstrating mastery of the cultural norms, values, and meaning that prevail within the MNC (Gorman, 2015). 
In addition, the large body of research on cross-national transfer of knowledge and practices suggests that the dominance of HQ leads to framing its knowledge as superior and as best practices (Ferner et al., 2012; Kostova, 1999). This places HQ actors in a privileged position allowing them to accumulate firm-specific cultural capital by defining what sort of knowledge and expertise is considered valuable within the MNC and by setting the rules according to which knowledge and expertise are judged and evaluated. Finally, the centrality of the home country culture and language also influences HQ actors' firm-specific cultural capital endowment (Levy et al., 2015). In hierarchical architecture elements of corporate culture and national culture are intertwined and mixed with each other (Storgaard, Tienari and Piekkari, 2014) and consequently firm-specific cultural capital involves elements of the home country. Therefore, HQ actors' adeptness in the MNC's home country culture, values, and language is an important source of firm-specific cultural capital. It can also foster communication and trust based on common culture and language (Harvey, Reiche, and Moeller, 2011).

In contrast, subsidiary actors in the hierarchical MNC have less influence over the rules of the organizational game and fewer opportunities to master it. They also have less exposure and practice at being the right kind of professional within the $\mathrm{MNC}$ - the meaning of which is often defined by powerful actors in the organization. Furthermore, subsidiary actors' knowledge and expertise are often framed as 'local' and viewed as narrower in scope and applicability (Ferner et al., 2012; Harzing, 2001). Finally, subsidiary actors are often less proficient in the home country culture and language and therefore possess lower levels of communication abilities and trust (Harzing, 2001).

The transition from hierarchical to network architecture can potentially create an integrated field of power where both HQ and subsidiary actors compete for domination. As a 
result, the composition of the dominant group is likely to change and include actors who are associated not only with HQ but also other MNC units, especially those that already have high levels of corporate embeddedness and strong links to HQ (Bouquet and Birkinshaw, 2008). Further, a common cultural currency is likely to emerge based on a meta-matrix that rank-orders the relative value of diverse cultural resources drawn from across the MNC. This matrix is also likely to regulate the rate at which the cultural capital of both HQ and subsidiary actors can be converted into symbolic capital and generate symbolic profits (Delmestri and Brumana, 2017). Thus, the definition of the legitimate firm-specific cultural capital is likely to become more inclusive, thereby diminishing the impact of the HQ and the home country. Even though the home country culture may continue to exert influence over firm-specific cultural capital, its influence is now considered as less legitimate and therefore often concealed and framed in more neutral terms as 'corporate culture' and 'discipline' (Storgaard et al., 2014). As a result of the decentralization of authority, HQ actors may see their power and influence eroding and therefore attempt to contest the transition and minimize its adverse effect on their social position.

With the influence of the HQ and home country culture somewhat waning, the content of firm-specific cultural capital is likely to capture the unique administrative heritage of the MNC, which reflects the history, cultural inclinations, deep-rooted internal structure and ways of conducting business (Bartlett and Ghoshal, 1989), and its dominant logic, which concerns the frames of reference and mindsets that senior MNC actors have developed over time as a result of interpreting and experiencing organizational situations (Prahalad and Bettis, 1986). These experiences bind together spatially dispersed parts of the MNC (Reiche et al., 2009) and establish the cognitive and normative 'rules of the game' that govern practices and interactions within the MNC. While HQ actors may still have an advantage, 
under network architecture both HQ and subsidiary actors can potentially become proficient in playing the organizational game and accumulate firm-specific cultural capital. This will be particularly the case for actors whose subsidiaries have competence-creating capabilities (Cantwell and Mudambi, 2005), maintain a strong business network (Andersson et al., 2007), or are able to influence the firm's administrative heritage and dominant logic through other means.

It is important to note that network architecture often brings together actors with diverse experiences. For example, Kristensen and Zeitlin's (2001) case-study research depicts the administrative heritage of the MNC as embedded in the experiences of local actors with playing the games of different national business systems and consequently as rather diverse. As a result, firm-specific cultural capital in network architecture likely consists of more widely sourced cultural dispositions and attributes, and is more unique to the MNC and to the particular constellation of external environments it operates in. Furthermore, the organizational game is likely to become more complex, involving a broader set of rules, resources, and rituals.

In sum, under hierarchical architecture HQ actors are more likely to accumulate firmspecific cultural capital that enables them to operate effectively within the MNC and compete for social positions. Subsidiary actors likely occupy a lower position in the social hierarchy and may experience marginalization and exclusion due to limited firm-specific cultural capital. In contrast, under network architecture HQ and subsidiary actors operate in an integrated field of power where they compete for social positions using a common cultural currency. However, HQ actors may still have a significant advantage due to the lasting impact of HQ and home country culture. 
The relative value of firm-specific and cosmopolitan cultural capital

In this section, we consider the relative value of firm-specific and cosmopolitan cultural capital in hierarchical and network architectures. In hierarchical architecture, firmspecific cultural capital is the dominant currency rather than cosmopolitan cultural capital. Further, as its content strongly reflects HQ and home country-related attributes, firm-specific cultural capital is an especially important currency for HQ actors. Thus, cosmopolitan cultural capital is relatively less important and possibly stands in direct competition with firm-specific cultural capital. In the case of HQ actors, individuals with high levels of both firm-specific and cosmopolitan cultural capital will likely face internal opposition from other high-status individuals who possess considerable firm-specific cultural capital but lack cosmopolitan cultural capital and therefore are compelled to protect their power in the organization from eroding (Kanter, 1995). To those latter actors, cosmopolitan cultural capital may threaten to diminish their own cultural capital endowment within the MNC, leading them to act to preserve the supremacy of their cultural capital or even enhance their position within the social hierarchy. They may do so by physically segregating actors with cosmopolitan cultural capital, for example through rearrangement of workspace or distribution of work assignments (Gray and Kish-Gephart, 2013), restricting access to firmspecific cultural capital (Bjerregaard and Klitmøller, 2016), or building a coalition of actors that excludes those with cosmopolitan cultural capital (Whitford and Zirpoli, 2016).

Under hierarchical architecture, subsidiary actors are peripheral participants in the competition for social positions and their firm-specific cultural capital, which is rather limited to begin with, carries little importance. Possessing cosmopolitan cultural capital is also unlikely to improve their standing in the social hierarchy. Without a detailed understanding of the normative and cognitive rules of the game, which govern practices and interactions within 
the MNC, these cosmopolitan actors may be perceived as out of touch with or even a threat to the company's cultural norms, meanings, and rituals. To the extent that other actors view such cosmopolitans as outsiders, they will attempt to inforce the orthodoxy on firm-specific cultural capital or call into question the value of cosmopolitan cultural capital in order to protect the current social hierarchy (Gray and Kish-Gephart, 2013).

In network architecture, both firm-specific cultural capital and cosmopolitan cultural capital are likely to serve as very important currencies for diverse actors in the competition for social positions in the MNC. In fact, the accumulation of firm-specific cultural capital by a wider group of actors, including subsidiary actors, enable the latter to play the corporate game through challenging the status quo (Bouquet and Birkinshaw, 2008), gaining centrality (Andersson et al., 2007), cross-boundary networking (Williams and Lee, 2011), issue selling (Dörrenbächer and Gammelgaard, 2016) or resistance and strong local support (Morgan and Kristensen, 2006).

Further, cosmopolitan cultural capital is likely to complement rather than compete with firm-specific cultural capital. Thus, actors' cosmopolitan cultural capital should further their chances of attaining a higher position in the MNC's social hierarchy. Specifically, to the extent that actors are proficient in the firm's cultural norms and practices and are therefore less likely viewed as outsiders (Cox, 1993) others will recognize these actors' cosmopolitan cultural resources, including diverse perspectives and experiences in other contexts, as more beneficial to achieving group-related tasks and goals (Haas, 2006). In this regard, we would expect relatively few restrictions in the transferability of cosmopolitan cultural capital across national MNC units because its value has been universalized (Igarashi and Saito, 2014). 
In principle, the three forms of capital (economic, social, and cultural) are mutually reinforcing and hence one form of capital can be converted into another, contingent on the established 'exchange rate' between forms of capital, which are field-specific (Bourdieu, 1986). Further, cultural capital can be converted into symbolic capital that affords legitimacy and prestige within the field. Thus, the conversion of cultural capital into social capital and symbolic capital is governed by the logic of the field that determines the going conversion rates (Bourdieu and Wacquant, 1992). Further, the three types of capital differ in liquidity and convertibility both within and across fields. In general, economic capital is considered the most liquid, most readily convertible and transferable. By comparison, the convertibility of social capital into economic capital is more difficult because social capital is less liquid and more contingent. Converting social into cultural capital may be difficult, whereas exchanging cultural into social capital is generally easier (Anheier et al., 1995).

As cultural capital is the dominant form of capital in hierarchical architecture, the relative value of firm-specific cultural capital is high and it can be converted into social capital and symbolic capital under a favourable 'exchange rate'. Thus, HQ actors who hold considerable firm-specific cultural capital can convert it into important social ties with powerful HQ actors, who can provide access to valuable resources and career opportunities (Granovetter, 1973; Reiche et al., 2009; Seibert et al., 2001). Additionally, they can generate symbolic profits in the form of prestige, honour, and reputation for the possession of extensive cultural capital (Bourdieu, 1986). In contrast, subsidiary actors will find it much harder to acquire social and symbolic capital because they lack the main currency in hierarchical architecture — cultural capital. In particular, social networks in hierarchical architecture are likely to be relatively homogeneous with regard to salient characteristics such as culture, nationality, and geographic location. Further, network ties among HQ actors based 
on shared cultural knowledge are likely to reinforce the social hierarchy, creating cycles of social closure (Coleman, 1990) and leading to the exclusion and marginalization of subsidiary actors who do not fit into the dominant culture. Consequently, the initial advantages that HQ actors obtain from their firm-specific cultural capital may further increase by accumulating intra-firm social capital. Network influence is therefore likely to reinforce the high-status position of HQ actors.

The transition from hierarchical to network architecture can potentially transform the 'rules of the game' that govern the 'exchange rate' between the various forms of capital (Delmestri and Brumana, 2017). In network architecture both cultural and social capital are important currencies, not only within the HQ organization but across the MNC, and are likely to be converted to one another with relative ease. Having the right cultural capital enables actors to create the social connections necessary for mobilizing relevant resources across the MNC network (see Lin et al., 1981). Similarly, because firm-specific cultural capital in network architecture is less a function of the HQ or the MNC's home country, the path to acquiring firm-specific cultural capital likely involves informal socialization channels such as social connections. Thus, interpersonal ties can help learn the ropes and develop proficiency in the MNC's unique culture, thereby fostering the accumulation of firm-specific cultural capital. In short, network architecture allows cultural capital and social capital to be mutually convertible. Further, both forms of capital can also be converted into symbolic capital and generate prestige and recognition across the MNC.

\section{Discussion}

In this study, we offer a theoretical framework for the role of cultural resources and political processes in structuring the social hierarchy in the MNC under two contrasting organizational architectures: hierarchical and network architecture. We suggest that cultural 
capital serves as an instrument of power and status within the MNC, underlying the social hierarchy and influencing access to valuable resources such as jobs, rewards, and opportunities. Therefore, cultural capital should be viewed as a symbolic marker that is used instrumentally for the reproduction of power relationships and symbolic boundaries between employee groups in the MNC.

Our framework further suggests that the transformation from hierarchical architecture towards network architecture sets in motion a high-stakes political struggle over the 'rules of the game' that order the social hierarchy in the MNC. What is at stake is nothing less than the capacity to determine which contrasting forms of cultural capital will become the most influential cards in the political game of status and power in the MNC. Thus, major organizational transformations are likely to create a global game of power where an increasing number of actors, holding different forms of capital, jockey for social positions in the field of power (Kristensen and Zeitlin, 2005). Our approach has major implications for theory, practice and future research.

\section{Theoretical implications}

First, we advance the IB literature by developing a conceptual framework that draws attention to the political role of culture in the MNC. Our approach departs from the conventional perspective on organizational politics and power in IB that often emphasizes functional, formal, and 'objective' sources of power within MNCs, to the exclusion of culture and agency (Geppert et al., 2016). In contrast, we focus on the more profoundly buried structure of relations between positions in the MNC-as-a-field and uncover the underlying forms of capital that generate and reproduce these regularities. Thus, we highlight the crucial distinction between official organizational positions, with their decreed powers, and the 
cultural capital that is actually held by occupants of these positions (Emirbayer and Johnson, 2008). While formal organizational positions confer authority and influence, many of the benefits accrued by their occupants are systemically generated not by the formal positions themselves, but by the capital endowment that actors bring with them to the post. Previous research has already highlighted the personal benefits generated by social capital and informal network ties (Lin et al., 1981), but has largely ignored the benefits generated by cultural capital. Specifically, formal organizational positions often serve to cloak a host of unearned benefits granted to privileged actors due to their symbolic capital in the form of legitimized cultural resources. Thus, our approach suggests that cultural capital not only provides access to high-status official positions, but is also partially to blame for the privileges and higher-than-normal returns that these positions often generate.

Further, a growing stream of literature in IB has pointed to the sources of political influence of subsidiaries within the MNC, including control of resources, legitimacy in the eyes of other outside actors, and network embeddedness (e.g., Andersson et al., 2007; Bouquet and Birkinshaw, 2008; Dörrenbächer and Gammelgaard, 2016). However, we still know little about the conditions under which this influence may wax or wane and about the ensuing struggle over cultural resources this may evoke. We address these questions by considering the political implications of changing organizational architecture. Our analysis points to how actors' locale-specific embeddedness within the MNC determines the type of cultural resources actors can leverage to attain a favourable position in the MNC's social hierarchy, and how changes in structural configuration may grant peripheral actors the agency to 'upgrade' their capital endowments and compete for social status.

Second, our framework has implications for the study of culture in IB that tends to focus on objective-like manifestations of culture (i.e., cultural norms, values, and practices) 
and supposedly inherent cultural differences. By contrast, we view culture as a political resource — and a potential constraint — of both individual and collective actors. As an individual resource, cultural capital can be used 'like aces in a game of cards' (Bourdieu, 1989: 17) in the competition for social positions, rewards, and opportunities. Furthermore, as the value of these trump cards is constantly at stake, individuals play the game to protect or upgrade the value of their capital endowment. This political dynamic goes beyond 'normal' corporate games because it impinges on the very rules that constitute the game in the first place. As a collective political resource, cultural capital is used instrumentally to structure access to valuable resources such as jobs, power, influence, and social connections. Under certain conditions, cultural capital can also constrain actors as in the case of cosmopolitan cultural capital in hierarchical architecture. As we argued, HQ actors who lack cosmopolitan cultural capital may act politically to preserve the supremacy of their cultural capital or even enhance their position within the social hierarchy relative to other HQ actors who possess cosmopolitan cultural capital.

Third and finally, our approach draws attention to the transnational dynamics that influence the accumulation and recognition of cultural capital. Traditionally, research on cultural capital has been conducted in nationally-bounded settings, particularly the educational system (e.g., Bourdieu and Passeron, 1979, 1990; DiMaggio, 1982; Katsillis and Rubinson, 1990). This focus reflects the fact that cultural capital is often accumulated and reproduced within the national educational system and is governed by national values and norms. Our framework, however, underscores two contemporary developments: the emergence of cosmopolitanism as cultural capital and the transnationalization of cultural capital. In recent years, research on cosmopolitanism has suggested that highly mobile professionals may accumulate cosmopolitan cultural capital and then use it to monopolize 
privileges and gain power over locals (Kanter, 1995; Levy, Peiperl and Jonsen, 2016). We suggest, however, that while cosmopolitan cultural capital has its value in MNCs, it does not yet operate as a trump card, outranking all other cultural resources. Instead, we argue that the relative value of cosmopolitan cultural capital within the MNC depends on locally embedded cultural resources, and on the structural configuration of the organization.

Cosmopolitan cultural capital may also be subject to processes of recognition, undervaluation, overvaluation and discontinuity when transported into a given firm because the relative value placed on cosmopolitan cultural capital vis-à-vis other cultural resources may differ across MNCs and over time. We suggest, however, that these processes occur primarily due to structural, strategic, and/or policy changes at the MNC level, and may reach beyond shifts in organizational architecture. For example, Neeley (2013) found that French and other non-native English-speaking employees working in a French high-tech company experienced a status loss after the organization instituted English as the lingua franca. Similarly, Birkinshaw, Crilly, Bouquet and Lee (2016) found that managers working in Asia experienced a substantial increase in their influence once the firm, originally headquartered in Amsterdam, established a second HQ in Beijing and moved towards a dual HQ model. Thus, once the organization undergoes significant transformations, the principles that govern the legitimization of cultural resources change as well, often reducing the value of cultural resources embedded in the HQ and the home country for ascending the social hierarchy in the MNC.

\section{Practical implications}

Our work also has implications for management practice. Specifically, our framework provides guidance for both individuals navigating their professional careers and organizations 
wishing to promote the integration of their workforce across cultural and symbolic boundaries. First, our theorizing suggests that firm-specific cultural capital is crucial for access to career opportunities and rewards. However, it also highlights that firm-specific cultural capital is unequally accumulated across the MNC and that some employees' access to valuable cultural capital is severely restricted due to their work location, previous experiences, and/or nationality, especially in the hierarchical architecture. These employees are at a further disadvantage when it comes to accumulating valuable social connections within the firm. For example, research on internal promotion versus external hiring shows that the job performance of external hires is, at least initially, lower compared to internally promoted candidates although the former tend to get paid more (Bidwell, 2011). These findings suggest that while external hires need to be compensated for their relatively stronger observable human capital they also lack firm-specific resources, including firm-specific cultural capital, relative to internal candidates, a lack that hinders their performance. Our theorizing also suggests that employees who don't have sufficient firm-specific cultural capital are better off looking for another job rather than waiting to accumulate firm-specific cultural capital in order to be promoted. Evidence indeed shows higher voluntary turnover rates for external compared to internal hires (Bidwell, 2011; Halaby, 1988).

Second, our analysis suggests that changes in MNC structural configuration-whether in response to external market conditions or in search of more effective mechanisms of control and coordination - have far-reaching implications for the relative distribution of actors' power and social positions within the MNC. When Samuel Palmisano took over as CEO of IBM in 2002, he decided to move the company away from a traditional, hierarchical MNC with its centre of gravity in the U.S. towards a 'globally integrated enterprise' with a network-based architecture (Kanter, 2009). The organizational transformation created 
flexible, country-based teams that would collaborate based on shared values. While strategic decision-making and control had previously occurred mainly at IBM's HQ — within a circle of HQ-based senior executives - decisions and information increasingly flowed laterally to and from those with the responsibility to serve individual customers. As a result, the content of IBM's firm-specific cultural capital shifted from relying on its home country culture and values to an amalgamation of company-specific values, cultural inclinations and ways of conducting business as the cognitive and normative rules of the game. The structural reconfiguration led foreign nationals born in emerging economies, who had successful careers in IBM in the U.S., to move back to their countries of origin because they perceived the local country operations - and their cross-unit interrelations - to be more influential than before. At the same time, the number of international assignments and rotations between IBM's various operations increased, which further generated cross-unit connections and developed cosmopolitan cultural capital among its managers (Kanter, 2009). Further, actors' struggle to maintain their relative capital endowments during a change in MNC structural configuration may slow down or in fact jeopardize such organizational transformation. MNCs would therefore be well advised to anticipate intra- and inter-unit political behavior, and broaden the set of cultural resources considered valuable in the organization before embarking on structural changes.

Third, our arguments point to a persistent influence of the home country, even in the case of an MNC's reconfiguration towards a network architecture. Indeed, research suggests that national diversity at the top of most MNCs, both at the CEO and the top management levels, remains low. On average, at least $85 \%$ of CEOs or top management team members of Fortune Global 500 companies are native to the country the corporation is headquartered in, which greatly limits career prospects for outsiders (Ghemawat and Vantrappen, 2015). 
Organizations wishing to promote the integration of their workforce and minimize ascriptive inequalities should provide opportunities for employees to accumulate firm-specific cultural capital by learning the informal rules of the game that govern the MNC. They should also make a concerted effort to define in a more inclusive way which cultural resources may be legitimate and valuable in the MNC. At the same time, MNCs need to be more proactive in their attempts to reduce the home country effect. Japanese company Rakuten is a case in point. With the goal to become a global company, its CEO decided to change Rakuten's official corporate language from Japanese to English (Neeley, 2011). The language change helped Rakuten to increase cross-border communication and achieve greater global integration across its various foreign operations, while also elevating the cultural resources of non-native organizational members, especially for English native speakers. Indeed, research has shown that a change of language mandate partially redistributes social status across its organizational members according to linguistic competence (e.g., Neeley, 2013) and hence serves as a means of reducing the influence of nationality.

\section{Directions for future research}

Finally, our conceptual work points to a number of relevant questions that, we hope, will stimulate future research and further advance our understanding in the areas of culture, power and politics in MNCs. We detail these questions below.

\section{How do local actors play global political games?}

Existing work on organizational politics in the MNC has largely focused on the organizational level, overlooking suborganizational and individual dynamics (Geppert et al., 2016). We suggest exploring how the locale-specific embeddedness of individual actors shapes the cultural resources they can leverage in the global corporate game and affects their bid for a higher position in the MNC's 
social hierarchy. Integral to this research direction is a more agentic and nuanced perspective on corporate games and the field of power in the MNC. We have suggested that actors marshal their capital in competing for domination over the field of power (Emirbayer and Johnson, 2008). However, playing the game may require far more astute gamesmanship than commonly realized because the field may be fragmented, diverse, and ambiguous, and therefore lends itself to multiple strategies and ploys. Furthermore, what are the rules, what is at stake, how domination is established, and the relative potency of various weapons and alliances may themselves be up for grabs. Delmestri and Brumana (2017), for example, suggest that actors play the game in order to accumulate symbolic capital and hence be perceived as a legitimate and worthy player by high status actors within the field of power. Kristensen and Zeitlin (2001) point to multiple games and rationalities clashing within the MNC. Studying this multiplicity of strategies and interpretations requires a contextualized engagement with players and games, and calls for research that draws on ethnographic and qualitative case study designs.

How do cultural and social capital work in tandem in MNCs? International business research has traditionally focused on social capital and the role of informal networks to study collaboration as well as the access and diffusion of resources in MNCs (e.g., Kostova and Roth, 2003; Reiche et al., 2009), to the exclusion of cultural capital. We encourage future research to consider the role of culture in the formation of social relationships in the MNC and the resultant access to resources embedded within these relationships. Thus, we suggest exploring the interplay between culture and social networks, two areas that have developed with little cross-pollination (Weber and Dacin, 2011). Similarly, as the interrelations between cultural and social capital are a function of an organization's particular structural configurations, future research should also consider how culture is converted into social 
capital and vice versa under different structural conditions. Further, what happens to the value of actors' inter-unit social capital when a MNC re-establishes a more hierarchical architecture, which continues to be widespread (Andersson and Holm, 2010)? At what rate does cosmopolitan cultural capital decay under these conditions? It would also be interesting to study the extent to which the interrelations between cultural and social capital apply to different types of MNCs, such as emerging market MNCs or born globals. For example, how salient are the HQ and the home country as sources of firm-specific cultural capital in these MNCs?

How does cultural capital operate across national borders? Cultural capital increasingly operates in a transnational context and on a global scale, and is transported across national borders. The rules that govern its recognition and legitimization are thus influenced by both local and global dynamics. This also means that the relative value of firmspecific and cosmopolitan cultural capital will depend on the specific cultural capital endowment of individual actors. Future research should therefore explore how the value of cultural capital appreciates or depreciates due to cross-border mobility or migration. For example, the value of formal educational credentials can severely depreciate because of lack of recognition in another country (Nowicka, 2014). Alternatively, transporting cultural capital across national borders may open up opportunities for some employees who are traditionally excluded due to a lack of appropriate cultural capital. Indeed, bicultural or immigrant employees often experience low returns on their credentials and competencies due to their outsider status or imperfect mastery of the home country culture, values, and language. Once these employees engage in transnational mobility or work in global teams, their bicultural experience however can become an asset (e.g., Kiesel and Haghirian, 2012). 


\section{Acknowledgements}

We thank the three anonymous reviewers and guest editors Stewart Clegg, Mike Geppert and Graham Hollinshead for their very constructive feedback and suggestions.

\section{Funding}

B Sebastian Reiche gratefully acknowledges the financial support of the Spanish Ministry of Economy and Competitiveness (grant number: ECO2015-68272-P).

\section{Notes}

${ }^{1}$ Bourdieu (1986) also identifies a third type of cultural capital: objectified cultural capital. This includes concrete goods that require embodied cultural capital to be appreciated and appropriated.

${ }^{2}$ In the cultural production world, common distinctions include 'high culture' and 'low culture,' 'elite culture' and 'popular culture,' and 'good taste' and 'vulgar taste' (Bourdieu, 1984).

\section{References}

Andersson U and Holm U (eds) (2010) Managing the contemporary multinational: The role of headquarters. Cheltenham, UK: Edward Elgar Publishing. 
Andersson U, Forsgren M and Holm U (2007) Balancing subsidiary influence in the federative MNC: A business network view. Journal of International Business Studies 38(5): $802-818$.

Anheier HK, Gerhards J and Romo FP (1995) Forms of capital and social structure in cultural fields: Examining Bourdieu's social topography. American Journal of Sociology 100(4): 859-903.

Bartlett CA and Ghoshal S (1989) Managing across borders: The transnational solution. Boston, MA: Harvard Business School Press.

Becker-Ritterspach F and Dörrenbächer C (2009) Intrafirm competition in multinational corporations: Towards a political framework. Competition \& Change 13(2): 199-213.

Bidwell M (2011) Paying more to get less: The effects of external hiring versus internal mobility. Administrative Science Quarterly 56(3): 369-407.

Birkinshaw JM and Morrison AJ (1995) Configurations of strategy and structure in subsidiaries of multinational corporations. Journal of International Business Studies 26(4): 729-753.

Birkinshaw J, Crilly D, Bouquet C and Lee SY (2016) How do firms manage strategic dualities? A process perspective. Academy of Management Discoveries 2(1): 51-78.

Bjerregaard T and Klitmøller A (2016) Conflictual practice sharing in the MNC: A theory of practice approach. Organization Studies 37(9), 1271-1295.

Bouquet C and Birkinshaw J (2008) Managing power in the multinational corporation: How low-power actors gain influence. Journal of Management 34(3), 477-508.

Bouquet C, Barsoux J-L and Levy O (2015) The perils of attention from headquarters. MIT Sloan Management Review 56(2): 16-18. 
Bourdieu P (1984) Distinction: A social critique of the judgement of taste. Boston: Harvard University Press.

Bourdieu P (1985) The social space and the genesis of groups. Theory and Society 14(6): 723-744.

Bourdieu P (1986) The forms of capital. In Richardson J (ed.) Handbook of theory and research for the sociology of education. Westport, CT Greenwood, 241-258.

Bourdieu P (1989) Social space and symbolic power. Sociological theory 7(1): 14-25.

Bourdieu P (2000) Pascalian meditations. Stanford: Stanford University Press.

Bourdieu P and Passeron J-C (1990) [1970] Reproduction in education, society and culture. Beverly Hills, CA: Sage.

Bourdieu P and Passeron J-C (1979) [1964] The inheritors: French students and their relation to culture. Chicago: University of Chicago Press.

Bourdieu P and Wacquant LJ (1992) An invitation to reflexive sociology. Chicago: University of Chicago Press.

Bourgouin F (2012) On being cosmopolitan: Lifestyle and identity of African finance professionals in Johannesburg. Ethnos 77(1): 50-71.

Boussebaa M and Morgan G (2014) Pushing the frontiers of critical international business studies: The multinational as a neo-imperial space. Critical Perspectives on International Business 10(1/2): 96-106.

Bühlmann F, David T and Mach A (2013). Cosmopolitan capital and the internationalization of the field of business elites: Evidence from the Swiss case. Cultural Sociology 7(2): 211-229.

Cantwell J and Mudambi R (2005) MNE competence-creating subsidiary mandates. Strategic Management Journal 26(12), 1109-1128. 
Clark E and Geppert M (2011) Subsidiary integration as identity construction and institution building: A political sensemaking approach. Journal of Management Studies 48(2): $365-416$.

Clegg SR (1989) Frameworks of power. London: Sage.

Coleman JS (1990) Foundations of social theory. Cambridge, MA: Harvard University Press.

Coté S (2011) How social class shapes thoughts and actions in organizations. Research in Organizational Behavior 31: 43-71.

Cox T Jr (1993) Cultural diversity in organizations: Theory, research, and practice. San Francisco: Berrett-Koehler Publishers.

Davies-Netzley SA (1998) Women above the glass ceiling: Perceptions on corporate mobility and strategies for success. Gender \& Society 12(3): 339-355.

Delmestri G and Brumana M (2017) The multinational corporation as a playing field of power: A Bourdieusian approach. In Dörrenbächer C and Geppert M (eds.) Multinational Corporations and Organization Theory: Post Millennium Perspectives. Research in the Sociology of Organizations (Vol. 49), Emerald Publishing, 325-353.

DiMaggio P (1982) Cultural capital and school success: The impact of status culture participation on the grades of US high school students. American Sociological Review 47(2): 189-201.

Dörrenbächer C and Gammelgaard J (2016) Subsidiary initiative-taking in multinational corpo-rations: The relationship between power and issue-selling. Organization Studies, 37(9): 1249-1270.

Doz Y, Santos J and Williamson P (2001) From global to metanational: How companies win in the knowledge economy. Cambridge, MA: Harvard Business School Press. 
Emirbayer M and Johnson V (2008) Bourdieu and organizational analysis. Theory and Society 37(1): 1-44.

Ferner A, Edwards T and Tempel A (2012) Power, institutions and the cross-national transfer of employment practices in multinationals. Human Relations 65(2): 163-187.

Friedman S, Laurison D and Miles A (2015) Breaking the 'class' ceiling? Social mobility into Britain's elite occupations. The Sociological Review 63(2): 259-289.

Fligstein N (1990) The transformation of corporate control. Cambridge, MA: Harvard University Press.

Geppert M and Dörrenbächer C (2014) Politics and power within multinational corporations: mainstream studies, emerging critical approaches and suggestions for future research. International Journal of Management Reviews 16(2): 226-244.

Geppert M, Becker-Ritterspach F and Mudambi R (2016) Politics and power in multinational companies: Integrating the international business and organization studies perspectives. Organization Studies 37(9): 1209-1225.

Ghemawat P and Vantrappen H (2015) How global is your C-suite? MIT Sloan Management Review 56(4): 73-82.

Gorman EH (2015) Getting ahead in professional organizations: Individual qualities, socioeconomic background and organizational context. Journal of Professions and Organization 2(2): 122-147.

Gould RV (2002) The origins of status hierarchies: A formal theory and empirical test. American Journal of Sociology 107(5): 1143-1178.

Granovetter M (1973) The strength of weak ties. American Journal of Sociology 78(6): 13601380. 
Gray B and Kish-Gephart JJ (2013) Encountering social class differences at work: How “class work” perpetuates inequality. Academy of Management Review 38(4): 670-699. Haas MR (2006) Acquiring and applying knowledge in transnational teams: The roles of cosmopolitans and locals. Organization Science 17(3): 367-384.

Halaby CN (1988) Action and information in the job mobility process: The search decision. American Sociological Review 53(1): 9-25.

Hardy C (1996) Understanding power: Bringing about strategic change. British Journal of Management 7(Supplement S1): S3-S16.

Harvey M, Reiche BS and Moeller M (2011) Developing effective global relationships through staffing with inpatriate managers: The role of interpersonal trust. Journal of International Management 17(2): 150-161.

Harzing A-W (2001) Who's in charge? An empirical study of executive staffing practices in foreign subsidiaries. Human Resource Management 40(2): 139-158.

Hedlund G (1993) Assumptions of hierarchy and heterarchy, with applications to the management of the multinational corporation. In Ghoshal S and Westney E (eds) Organization theory and multinational corporation. Hampshire: MacMillan, 211-236.

Igarashi H and Saito H (2014) Cosmopolitanism as cultural capital: Exploring the intersection of globalization, education and stratification. Cultural Sociology 8(3): 222-239.

Kanter RM (1995) World class: Thriving locally in the global economy. New York: Simon and Schuster.

Kanter RM (2009) IBM in the 21st century: The coming of the globally integrated enterprise. Harvard Business School Case \#9-308-105, Harvard Business School Publishing: Boston, MA. 
Kaplan V (2006) Structural inequality: Black architects in the United States. Lanham, MD: Rowman \& Littlefield.

Katsillis J and Rubinson R (1990) Cultural capital, student achievement, and educational reproduction: The case of Greece. American Sociological Review 55(2): 270-279.

Kay FM and Hagan J (1998) Raising the bar: The gender stratification of law-firm capital. American Sociological Review 63(5): 728-743.

Kerr R and Robinson S (2016) Architecture, symbolic capital and elite mobilisations: The case of the Royal Bank of Scotland corporate campus. Organization 23(5): 699-721.

Kiesel K and Haghirian P (2012) Bicultural managers and their role in multinational corporations: An exploratory study in Japan. In Christiansen B (ed) Cultural variations and business performance: Contemporary globalism. Hershey, PA: Business Science Reference, 43-55.

Kim J (2011) Aspiration for global cultural capital in the stratified realm of global higher education: Why do Korean students go to US graduate schools? British Journal of Sociology of Education 32(1): 109-126.

Kostova T (1999) Transnational transfer of strategic organizational practices: A contextual perspective. Academy of Management Review 24(2): 308-324.

Kostova T and Roth K (2003) Social capital in multinational corporations and a micro-macro model of its formation. Academy of Management Review 28(2): 297- 317.

Kristensen PH and Zeitlin J (2005) Local players in global games. Oxford, UK: Oxford University Press.

Kristensen PH and Zeitlin J (2001) The making of a global firm: Local pathways to multinational enterprise. In Morgan G, Kristensen PH and Whitley R (eds) The 
multinational firm: Organizing across institutional and national divides. Oxford: Oxford University Press, 172-195.

Lamont M and Lareau A (1988) Cultural capital: Allusions, gaps and glissandos in recent theoretical developments. Sociological Theory 6(2): 153-168.

Lamont M and Molnár V (2002) The study of boundaries in the social sciences. Annual Review of Sociology 28: 167-195.

Lareau A (2015) Cultural knowledge and social inequality. American Sociological Review 80(1): 1-27.

Lareau A and Weininger EB (2003) Cultural capital in educational research: A critical assessment. Theory and Society 32(5-6): 567-606.

Levy O, Taylor S, Boyacigiller NA, Bodner TE, Peiperl MA and Beechler S (2015) Perceived senior leadership opportunities in MNCs: The effect of social hierarchy and capital. Journal of International Business Studies 46(3): 285-307.

Levy O, Peiperl MA and Jonsen K (2016) Cosmopolitanism in a globalized world: An interdisciplinary perspective. In Osland J, Li M and Mendenhall M (eds) Advances in Global Leadership, Vol. 9. New York: Emerald Group Publishing, 279-321.

Lin N, Ensel WM and Vaughn JC (1981) Social resources and strength of ties. American Sociological Review 46(4): 393-405.

Lukes S (2005) Power: A radical view ( $2^{\text {nd }}$ ed.). London: Palgrave-MacMillan.

Magee JC and Galinsky AD (2008) Social hierarchy: The self-reinforcing nature of power and status. Academy of Management Annals 2(1): 351-398.

Martinez JI and Jarillo JC (1989) The evolution of coordination mechanisms in multinational corporations. Journal of International Business Studies 20(3): 489-514. 
Menz M, Kunisch S and Collis DJ (2015) The corporate headquarters in the contemporary corporation: Advancing a multimarket firm perspective. Academy of Management Annals 9: 633-714.

Morgan G and Kristensen PH (2006) The contested social space of multinationals: Varieties of institutionalism, varieties of capitalism. Human Relations, 59(11): 1467-1490.

Mudambi R and Navarra P (2004) Is knowledge power? Knowledge flows, subsidiary power and rent-seeking within MNCs. Journal of International Business Studies 35(5): $385-$ 406.

Neeley T (2011) Language and globalization: "Englishnization" at Rakuten. Harvard Business School Case \#9-412-002, Harvard Business School Publishing: Boston, MA.

Neeley TB (2013) Language matters: Status loss and achieved status distinctions in global organizations. Organization Science 24(2): 476-497.

Nohria N and Ghoshal S (1994) Differentiated fit and shared values: Alternatives for managing HQ-subsidiary relations. Strategic Management Journal 15(6): 491-502.

Nowicka M (2014) Migrating skills, skilled migrants and migration skills: The influence of contexts on the validation of migrants' skills. Migration Letters 11(2): 171-186.

Oakes S, Townley B and Cooper DJ (1998) Business planning as pedagogy: Language and control in a changing institutional field. Administrative Science Quarterly, 43(2): 257292.

Orton JD and Weick KE (1990) Loosely coupled systems: A reconceptualization. Academy of Management Review 15(2): 203-223.

Palonen K (2003) Four times of politics: Policy, polity, politicking, and politicization. Alternatives: Global, Local, Political 28(2), 171-186. 
Prahalad CK and Bettis RA (1986) The dominant logic: A new linkage between diversity and performance. Strategic Management Journal 7(6): 485-501.

Prahalad CK and Doz Y (1987) The multinational mission: Balancing local demands and global vision. New York, NY: The Free Press.

Prieur A and Savage M (2013) Emerging forms of cultural capital. European Societies 15(2): 246-267.

Purcell D (2013) Baseball, beer, and Bulgari: Examining cultural capital and gender inequality in a retail fashion corporation. Journal of Contemporary Ethnography 42(3): 291-319.

Reiche BS, Harzing A-W and Kraimer ML (2009) The role of international assignees' social capital in creating inter-unit intellectual capital: A cross-level model. Journal of International Business Studies 40(3): 509-526.

Rivera LA (2012) Hiring as cultural matching: The case of elite professional service firms. American Sociological Review 77(6): 999-1022.

Robbins D (2005) The origins, early development and status of Bourdieu's concept of “cultural capital." The British Journal of Sociology 56(1): 13-30.

Sauder M, Lynn F and Podolny JM (2012) Status: Insights from organizational sociology. Annual Review of Sociology 38: 267-283.

Seibert SE, Kraimer ML and Liden RC (2001) A social capital theory of career success. Academy of Management Journal 44(2): 219-237.

Simpson, B., Willer, R. and Ridgeway, C. L. (2012). Status hierarchies and the organization of collective action. Sociological Theory, 30(3): 149-166.

Storgaard M, Tienari J and Piekkari R (2014) “The most public secret”: Concealing and silencing ethnocentrism in the MNC. In Pedersen T, Venzin M, Devinney TM and 
Tihanyi L (eds) Orchestration of the global network organization. Advances in International Management, Vol. 27. New York: Emerald Group Publishing, 191-212. Stuber J (2005) Asset and liability? The importance of context in the occupational experiences of upwardly mobile White adults. Sociological Forum 20(1): 139-166.

Swartz D (1997) Culture and power: The sociology of Pierre Bourdieu. Chicago: University of Chicago Press.

The Economist (2015) L'exception française. Published online April 8, 2015.

\section{http://www.economist.com/whichmba/lexception-fran-aise}

Vaara E, Tienari J and Säntti R (2003) The international match: Metaphors as vehicles of social identity-building in cross-border mergers. Human Relations 56(4): 419-451.

Weber K and Dacin MT (2011) The cultural construction of organizational life: Introduction to the special issue. Organization Science 22(2): 287-298.

Weenink D (2008) Cosmopolitanism as a form of capital parents preparing their children for a globalizing world. Sociology 42(6): 1089-1106.

Westney DE (2009) The multinational firm as an evolutionary system. In Collison S and Morgan G (eds) Images of the multinational firm. Wiley: Chichester, UK, 117-144.

Whitford J and Zirpoli F (2016) The network firm as a political coalition. Organization Studies 37(9): 1227-1248.

Williams C and Lee SH (2011) Political heterarchy and dispersed entrepreneurship in the MNC. Journal of Management Studies 48(6): 1243-1268. 
Table 1. Hierarchical and network multinational corporation architectures

\begin{tabular}{|c|c|c|}
\hline Characteristic & Hierarchical architecture & Network architecture \\
\hline uthority & $\begin{array}{l}\text { Managerial capabilities, resources and } \\
\text { decision-making are concentrated at HQ }\end{array}$ & $\begin{array}{l}\text { Managerial capabilities, resources and } \\
\text { decision-making are dispersed throughout the } \\
\text { MNC }\end{array}$ \\
\hline $\begin{array}{l}\text { Range of resource } \\
\text { mobilization }\end{array}$ & $\begin{array}{l}\text { - Vertical flows of people, products and } \\
\text { knowledge }\end{array}$ & $\begin{array}{l}\text { - Lateral and vertical flows of people, products } \\
\text { and knowledge }\end{array}$ \\
\hline $\begin{array}{l}\text { Coordination and control } \\
\text { mechanisms }\end{array}$ & $\begin{array}{l}\text { - Primarily structural and formal mechanisms; } \\
\text { focus on calculative means }\end{array}$ & $\begin{array}{l}\text { - Relatively more informal and subtle } \\
\text { mechanisms; focus on normative integration }\end{array}$ \\
\hline
\end{tabular}


Table 2. Cultural capital and multinational corporation architecture

\begin{tabular}{|c|c|c|}
\hline Cha & Hiera & Network : \\
\hline Do & $\mathrm{Q}$ ac & HQ a \\
\hline $\begin{array}{l}\text { Dominant form(s) of } \\
\text { capital }\end{array}$ & $\begin{array}{l}\text { - Cultural capital } \\
\text { - Informal social hierarchy in MNC is reflected in } \\
\text { formal organizational hierarchy (both are } \\
\text { mutually constitutive) } \\
\text { - Cultural capital acts as coordination and control } \\
\text { mechanism within HQ }\end{array}$ & $\begin{array}{l}\text { - Social and cultural capital } \\
\text { - Lateral and decentralized structure creates need } \\
\text { for informal mechanisms of coordination and } \\
\text { control } \\
\text { - Cultural capital acts as coordination and control } \\
\text { mechanism across the MNC }\end{array}$ \\
\hline $\begin{array}{l}\text { Locus and content of } \\
\text { firm-specific cultural } \\
\text { capital }\end{array}$ & $\begin{array}{l}\text { - Firm-specific cultural capital resides at HQ and } \\
\text { reflects culture of HQ actors } \\
\text { - Firm-specific cultural capital reflects culture of } \\
\text { home country }\end{array}$ & $\begin{array}{l}\text { - Firm-specific cultural capital resides at level of } \\
\text { MNC and reflects culture of diverse MNC actors } \\
\text { - Firm-specific cultural capital reflects } \\
\text { administrative heritage and organizational } \\
\text { culture/identity of MNC }\end{array}$ \\
\hline $\begin{array}{l}\text { Relative value of } \\
\text { firm-specific and }\end{array}$ & $\begin{array}{l}\text { - Firm-specific cultural capital is important for } \\
\text { HQ actors but not for subsidiary actors }\end{array}$ & $\begin{array}{l}\text { - Firm-specific cultural capital is important across } \\
\text { the MNC }\end{array}$ \\
\hline $\begin{array}{l}\text { cosmopolitan cultural } \\
\text { capital }\end{array}$ & $\begin{array}{l}\text { - Cosmopolitan cultural capital carries little } \\
\text { importance }\end{array}$ & - Cosmopolitan cultural capital carries importance \\
\hline $\begin{array}{l}\text { Conversion of cultural } \\
\text { capital }\end{array}$ & $\begin{array}{l}\text { - Cultural capital can be converted to social } \\
\text { capital within the HQ }\end{array}$ & $\begin{array}{l}\text { - Cultural and social capital are mutually } \\
\text { convertible }\end{array}$ \\
\hline
\end{tabular}


Orly Levy (PhD in sociology, University of Wisconsin-Madison) is Reader in International Organizational Behavior at Cranfield School of Management, Cranfield University, United Kingdom. Her research focuses on the cultural, cognitive, and relational dimensions of global organizations and transnational networks. She studies managerial cognition, leadership, and organizational culture in multinational corporations, cosmopolitanism in theory and practice, and transnational social and cultural capital. Her work has appeared in journals such as Journal of International Business Studies, Sloan Management Review, and Journal of Organizational Behavior. [Email: o.levy@cranfield.ac.uk]

B. Sebastian Reiche (PhD in management, University of Melbourne) is Associate Professor and Department Chair of Managing People in Organizations at IESE Business School in Barcelona, Spain. His research focuses on the forms, prerequisites and consequences of global work, international HRM, global leadership and knowledge transfer. His research has appeared in a variety of outlets, including Journal of International Business Studies, Personnel Psychology, Journal of Management Studies, Academy of Management Discoveries and Human Resource Management. He is also co-editor, with Guenter Stahl, Mark Mendenhall and Gary Oddou, of Readings and Cases in International Human Resource Management ( $6^{\text {th }}$ edition, Routledge), and co-editor, with Helene Tenzer and Anne-Wil Harzing, of International Human Resource Management ( $5^{\text {th }}$ edition, Sage). He is Associate Editor of Human Resource Management Journal and regularly blogs on topics related to expatriation and global work (http://blog.iese.edu/expatriatus). [Email: sreiche@iese.edu]

\section{Corresponding Author:}

B Sebastian Reiche

Department of Managing People in Organizations

IESE Business School

Ave. Pearson 21

Barcelona 08034

Spain

sreiche@iese.edu

\section{Other Author(s):}

Orly Levy

School of Management 
Cranfield University

Cranfield

UK

o.levy@cranfield.ac.uk 